\title{
HTLV Type 1 Molecular Study in Brazilian Villages with African Characteristics Giving Support to the Post-Columbian Introduction Hypothesis
}

\author{
Filipe Ferreira de Almeida Rego, ${ }^{1,2}$ Luiz Carlos Junior Alcantara, ${ }^{1,2}$ Jose Pereira Moura Neto, ${ }^{3}$ \\ Aline Cristina Andrade Mota Miranda, ${ }^{2}$ Osmario de Souza Pereira, ${ }^{3}$ Marilda de Souza Gonçalves, ${ }^{3}$ \\ and Bernardo Galvão-Castro1,2
}

\begin{abstract}
We performed an HTLV epidemiological study of 986 individuals from 17 villages from the same state of Salvador, the city with the highest HTLV-1 prevalence in Brazil. The HTLV-1 prevalence was 3.85\%, $1.56 \%$, and $1.23 \%$ in three villages. Phylogenetic analysis of the LTR region demonstrated that all positive samples analyzed belonged to the Transcontinental subgroup of the HTLV-1 Cosmopolitan subtype. Three of the new HTLV1 sequences formed a well-supported clade within one of the Latin American clusters that contain a South African sequence. This Latin American cluster that segregated from the same ancestor as the other clade contained a Central African sequence. This ancestral relationship could support our previous report that suggests that this subgroup was first introduced into South Africa as a result of the migration of the Bantu population from Central Africa to Southern Africa over the past 3000 years, and afterward to Brazil during the slave trade between the sixteenth and nineteenth centuries.
\end{abstract}

$\mathbf{H}$ TLV-1 INFECTS APPROXIMATELY 11 TO 20 MILLION PEOPLE WORLDWIDE, ${ }^{1}$ and is endemic in areas such as Japan, ${ }^{2}$ Central African regions, ${ }^{3}$ the Caribbean, ${ }^{4}$ and some areas of Latin America. ${ }^{5}$ Phylogenetic analysis of the LTR region has classified HTLV-1 into seven subtypes: a or cosmopolitan, ${ }^{6}$ b or Central African, ${ }^{7}$ c or Melanesian, ${ }^{8} \mathrm{~d}$, from Cameroon, ${ }^{9}$ e, from the Democratic Republic of Congo, ${ }^{10} \mathrm{f}$, from an individual from Gabon, ${ }^{10}$ and g, recently described as a new subtype in Cameroon. ${ }^{11}$ The cosmopolitan subtype can be divided in five subgroups: A, Transcontinental; B, Japanese; C, West African; D, North African; ${ }^{6}$ and E, Peruvian. ${ }^{12}$

Previous studies have suggested that HTLV-1 was brought to Salvador, a Brazilian city in the state of Bahia, during the slave trade. ${ }^{12,13}$ The highest prevalence of this virus in the country can be found here, $1.35 \%$ among blood donors and $1.8 \%$ in the general population. ${ }^{14,15}$ This can be explained by the fact that many Africans were brought here to work as slaves and their descendents have given the state its current sociodemographic and ethnic characteristics, which are similar to those of some African cities. Today most of the HTLV-1 molecular characterization studies in Brazil have been performed in sequences from Salvador.
To gain further insight into the history of HTLV-1 in the state of Bahia, we carried out a molecular epidemiological study in villages surrounding eight towns in the state.

This study was approved by the Committee of Ethics in Human Research as part of the project "Quality of water and health: evaluation and impact in the semi-arid region of Bahia state."

Our study was run in the towns of Campo Formoso, Jacobina, Juazeiro, Mirangaba, Morro do Chapéu, Umburanas, Várzea Nova, and Ourolândia, all located in the São Francisco river basin in Bahia (Fig. 1). The participants in the project signed an informed consent and minors under 18 years participated only with the consent of a responsible adult. To investigate the HTLV-1 seroprevalence, we collected blood samples from 986 individuals from 17 localities: Laje dos Negros (97), Pacuí (115), Abreus (56), and Curral Velho (89) from Campo Formoso; Caatinga do Moura (61) and Salinas (49) from Jacobina; Alegre (64), Junco (81), and Campo dos Cavalos (89) from Juazeiro; Taquarendi (104) from Mirangaba; Tamboril (78) from Morro do Chapéu; Delfino (90) from Umburanas and Barriguda de Cima (10); and Sede (3) from Várzea Nova.

\footnotetext{
${ }^{1}$ Bahia School of Medicine and Public Health/Bahia Foundation for Development of Science, Salvador, Bahia, Brazil.

${ }^{2}$ Advanced Public Health Laboratory, Gonçalo Moniz Research Center, Oswaldo Cruz Foundation, Salvador, Bahia, Brazil.

${ }^{3}$ Pathology and Molecular Biology Laboratory, Gonçalo Moniz Research Center, Oswaldo Cruz Foundation, Salvador, Bahia, Brazil.
} 


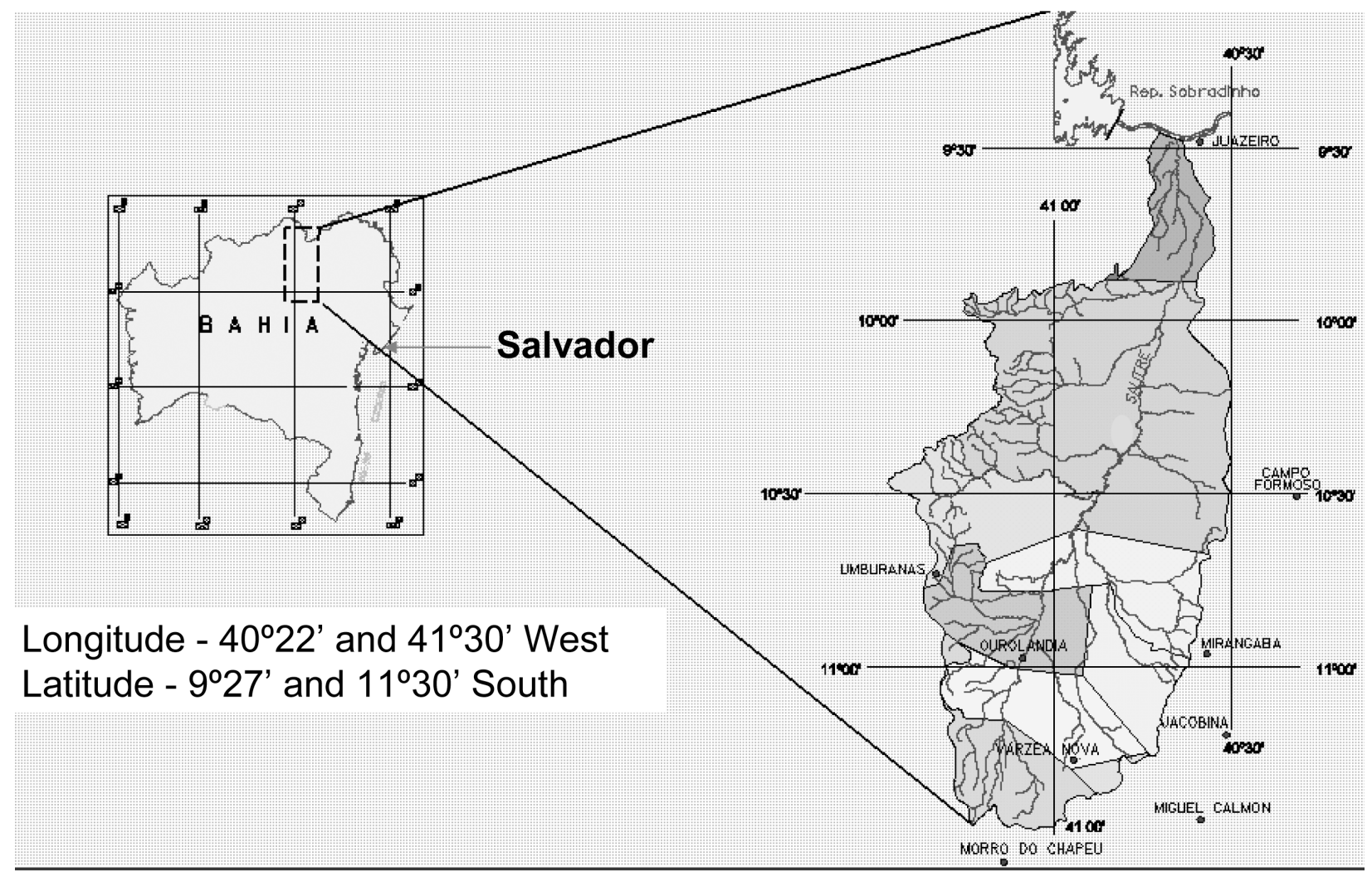

FIG. 1. Bahia state map highlighting the geographic location of the study region in the São Francisco river basin.

All samples were submitted to ELISA (ORTHO HTLV-1/ HTLV-2) and Western blot (HTLV WB 2.4; Genelabs Diagnostics, Singapore). The HTLV1/2 pol gene nested polymerase chain reaction (PCR) was performed in the indeterminate samples as previously described. ${ }^{16}$ DNA from five reactive samples was extracted from total blood using the QIAGEN kit (QIAamp DNA Blood Kit) and the nested PCR of the HTLV-1 long terminal repeat (LTR) region was performed. ${ }^{13}$ The LTR amplification products were purified using the QIAquick Gel Extraction kit (Qiagen) and sequenced directly on an automated 3100 genetic analyzer (Applied Biosystems Inc., Foster City, CA) using the same inner primers. The new LTR sequences and selected reference sequences downloaded from the GenBank/EMBL database were aligned using the ClustalX software ${ }^{17}$ and manually edited using the GeneDoc program. ${ }^{18}$ Phylogenetic trees were generated using the neighbor-joining (NJ) and maximum-likelihood (ML) methods of PAUP* software version 4.0b10. ${ }^{19}$ The Tamura-Nei evolutionary model with gamma distribution was selected as the best model (alpha parameter $=0.5124$ ) using the Modeltest 3.7 software. ${ }^{20}$ The NJ tree was constructed with an optimized nucleotide substitution rate matrix and a $\gamma$-shape parameter, using empirical base frequencies. The reliability of the NJ trees was assessed by analyzing 1000 bootstrap replicates. For ML trees, a heuristic search was performed using the NJ tree as a start, including its optimized parameters. The likelihood ratio test method was used to calculate the statistical support (expressed in $p$-values) for the branches. Trees were drawn with TreeView, version 1.4. Means of genetic distances among
HTLV-1 isolates were measured using the Tamura-Nei substitution model, implemented in the Mega3 software. ${ }^{21}$

The HTLV-1 prevalence rates in the three villages (Taquarendi, Junco, and Alegre) were 3.85\% (4), 1.23\% (1), and $1.56 \%(1)$, respectively. No sample was positive for HTLV-2. The mean age of the infected individuals was 44 (16-57) and five of them were women. The only infected man (VSF310) had received three blood transfusions, and his exwife was also HTLV-1 seropositive (VSF279) and her mother was HTLV seronegative. One of the six blood samples was not sufficient for DNA extraction and molecular analysis.

The phylogenetic analysis classified all isolates as the Transcontinental subgroup of the Cosmopolitan subtype with a bootstrap of $73 \%$ and also ML branch length statistical support ( $p<0.001$ ) (Fig. 2). Three of them were grouped in the Latin American cluster B with bootstrap support of $78 \%$ and $p<0.001$ in ML. Within this cluster we observed an isolate from South Africa (HTLV24). Furthermore, this monophyletic group shares a common ancestor with a Central African isolate from the Cameroon (2472LE), in spite of the lack of bootstrap value and $p$ value in the branch that connects the two referred monophyletic groups. One of the sequences was not grouped inside the Latin American clusters, and another was classified in Latin American cluster A, with no bootstrap support, but statistically significant in ML $(p<0.001)$.

The mean diversity in the São Francisco river basin sequences was $1.3 \%$, and among them and other Brazilian sequences it was $1.5 \%$. Comparing the VSF273 sequence with all the sequences of the Latin American cluster A and B, we 
identified $1.5 \%$ and $1.4 \%$ of mean diversity, respectively. The mean diversity observed when we compared the sequence from the isolate VSF287 with all other sequences of the Latin American cluster A was $0.7 \%$. In addition, comparing the three new sequences of the Latin American cluster B with all other sequences of this cluster, we found a mean diversity of $1.0 \%$.

Our results suggest that HTLV-1 infection is spreading from Salvador to other regions of the state of Bahia. This is corroborated when we compare the prevalence rate between Salvador ${ }^{15}$ and the three villages, $1.23-3.85 \%$, and also when we observe the presence of the sequence from the isolate FNN148 from Salvador in the phylogenetic tree topology in the Latin American cluster B, segregated within three new sequences from São Francisco villages (Fig. 2). Therefore, the HTLV-1 seroprevalence rate, described in this study, could be underestimated in these populations, as we screened only a small number of samples from each village. A seroepidemiological inquiry would therefore be necessary to confirm this observation. Because of the frequency of HTLV-1 infection and the severity of the associated diseases, it should be considered a public health concern in the state of Bahia and action to limit its spread should be taken.

The phylogenetic analyses also suggest horizontal transmission between two individuals from Taquarandi (VSF310 and VSF279), but further analyses are necessary to confirm this hypothesis. Given these results, we conclude that HTLV prevention campaigns are important in this region.

Our study confirms, as previously described,13,22,23 that the HTLV-1 Transcontinental subgroup of the Cosmopolitan subtype is also the most prevalent strain in Brazil. The presence of HTLV-1 LTR sequences from Bahia in different clusters in the phylogenetic tree suggests multiple introductions of HTLV-1 in our population, as previously described. The isolate VSF273 was not clustered into the described Latin American groups, supporting our previous studies suggesting that the Brazilian HTLV-1 isolates are the result of multiple post-Columbian introductions in our country. This post-Columbian introduction hypothesis could also be supported by the close relationship among some HTLV-1 Latin American strains, including our new sequences and the new Peruvian sequences, ${ }^{24}$ with some South African strains.

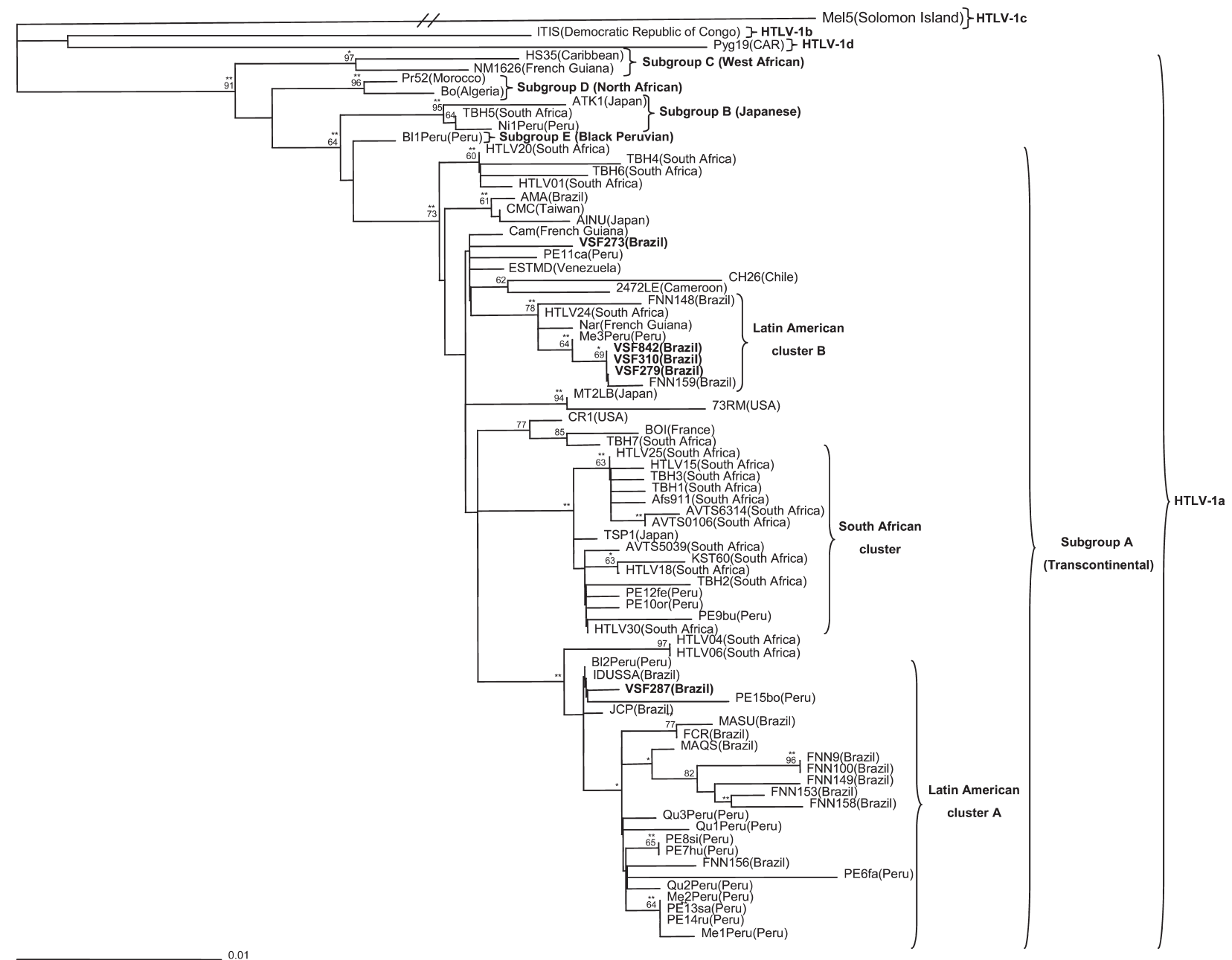

FIG. 2. Rooted neighbor-joining tree of 79 HTLV-1 strains based on a 613-bp fragment of the LTR region. The bootstrap values ( $>60 \%$ and using 1000 bootstrap samples) on the branches represent the percentage of trees for which the sequences located at the right end of the branch form a monophyletic group. Mel5 was used as an outgroup. The geographic origin is given in parentheses. Newly sequenced LTRs included in this analysis are in bold. The ML method was highly statistically significant $\left({ }^{* *} p<0.001\right)$ or statistically significant $\left({ }^{*} p<0.005\right)$, respectively. 
In our previous publications ${ }^{13,23}$ we suggest that the introduction of this subgroup is most probably the result of the migration of the Bantu population in the past 3000 years from Central Africa to Southern Africa, giving rise to the Zulu people, or due to a more recent migration (less than 300 years ago) to the gold mines in South Africa.

Our new HTLV-1 isolates were characterized by low diversity levels in the LTR region. The results also suggest a recent introduction of this virus in those regions, lending support to previous studies suggesting the post-Columbian introduction of this virus in Bahia through the slave trade from South Africa between the sixteenth and nineteenth centuries.

This seems consistent when we observe that one sequence from the Central African region and another from Chile share a common ancestor that segregated within the Latin American cluster B, which also has a sequence from South Africa in the tree topology.

African people from Bantu-speaking areas were the first slaves to be exported on a large scale to Bahia, bringing with them their strong cultural heritage still present in the language, religion, folklore, and customs of Bahia today. Although the majority of the Africans brought to Bahia during the slave trade came from West Africa (Benin, Nigeria, and northern Angola), there is evidence that slaves were also brought from other regions of the southern African continent (e.g., Madagascar, Mozambique, and southern Angola). Therefore, infected South Africans could have introduced the HTLV-1 Cosmopolitan subtype of the Transcontinental subgroup into Salvador and possibly into other areas in the Latin American continent. A possible connection with other Bantuspeaking groups should be investigated by analyzing more HTLV-1 isolates from Central Africa.

\section{Sequence Data}

The GenBank accession numbers of the new HTLV-1 fragments included in the phylogenetic study were as follows: EF672333, EF672334, EF672335, EF672336, and EF672337.

\section{Acknowledgments}

The bioinformatics analysis was performed in the Bioinformatics Unit of the LASP/CPqGM/FIOCRUZ, supported by FAPESB (Grants 303/03) and the Brazilian Ministry of Health (306/04 and 307/04). The authors are grateful to Noilson Lázaro de Souza Gonçalves and Elisabeth De Liege for technical assistance.

\section{References}

1. Catalan-Soares B, Proietti FA, and Carneiro-Proietti AB: Heterogeneous distribution of $\mathrm{HTLV}-1 / \mathrm{II}$ prevalence rates in blood donors from urban areas in Brazil. Vox Sang 2004;87(3):105.

2. Kajiyama W, Kashiwagi S, Nomura H, Ikematsu H, Hayashi $\mathrm{J}$, and Ikematsu W: Seroepidemiologic study of antibody to adult T-cell leukemia virus in Okinawa, Japan. Am J Epidemiol 1986;123(5):41-47.

3. Verdier M, Bonis J, and Denis FA: The prevalence and incidence of HTLV in Africa. AIDS Africa 1994;9:173-193.

4. Blattner WA, Saxiger DC, Riedel B, et al.: A study of HTLV$\mathrm{I}$ and its associated risk factors in Trinidad and Tobago. J
Acquir Immune Defic Syndr Hum Retrovirol 1990;3:11021108.

5. Proietti FA, Carneiro-Proietti ABF, Catalan-Soares BC, and Murphy EL: Global epidemiology of HTLV-I infection and associated diseases. Oncogene 2005;24:6058-6068.

6. Miura T, Fukunaga T, and Igarashi T: Phylogenetic subtypes of human T-lymphotropic virus type I and their relations to the anthropological background. Proc Natl Acad Sci USA 1994;91:1124-1127.

7. Vandamme A-M, Liu H-F, Goubau P, and Desmyter J: Primate T-lymphotropic virus type I LTR sequence variation and its phylogenetic analysis: Compatibility with an African origin of PTLV-I. Virology 1994;202:212-223.

8. Gessain A, Yanagihara R, Francini G, et al.: Highly divergent molecular variants of human T-lymphotropic virus type from isolated populations in Papua New Guinea and the Solomon Islands. Proc Natl Acad Sci USA 1991;88:76947698.

9. Chen J, Zekeng L, Yamashita M, et al.: HTLV isolated from a pygmy in Cameroon is related but distinct from the known Central African type. AIDS Res Hum Retroviruses 1995;11: 1529-1531.

10. Salemi M, Van Dooren S, Audenaert E, et al.: Two new human T-lymphotropic virus type I phylogenetic subtypes in seroindeterminates, a Mbuti pygmy and a Gabonese, have closest relatives among African STLV-I strains. Virology 1998;246:277-287.

11. Wolfe ND, Heneine W, Carr JK, et al.: Emergence of unique primate T-lymphotropic viruses among central African bushmeat hunters. Proc Natl Acad Sci USA 2005;102(22): 7994-7999.

12. Van Dooren, S, Gotuzzo E, Salemi M, et al.: Evidence for a post-Colombian introduction of human T-cell lymphotropic virus in Latin America. J Gen Virol 1998;79:2695-2708

13. Alcantara LCJ, Oliveira T, Gordon M, et al.: Tracing the origin of Brazilian HTLV-1 as determined by analysis of host and viral genes. AIDS 2006;20:780-782.

14. Galvão-Castro B, Loures L, Rodrigues LGM, et al.: Geographic distribution of human-T lymphotropic virus type-I among blood donors: A Brazilian nationwide study. Transfusion 1997;37:242.

15. Dourado I, Alcantara LCJ, Barreto ML, Teixeira MG, and Galvão-Castro B: HTLV-I in the general population of Salvador, Brazil: A city with African ethnic and sociodemographic characteristics. J Acquir Immune Defic Syndr 2003; 34:527-531.

16. Vallejo A and García-Sáiz, A: Typing human T-cell lymphotropic virus (HTLV-I and HTLV-II) by nested polymerase chain reaction: Application to clinical specimens. J Virol Methods 1995;51(1):9-17.

17. Xia X: Dambe: Data analysis in molecular biology and evolution. Department of Ecology and Biodiversity, University of Hong Kong, Hong Kong, 2000.

18. Nicholas KB, Nicholas HBJ, and Deerfield DW: GeneDoc: Analysis and visualization of genetic variation. Embnew News 1997;30.

19. Swofford DL, Olsen GJ, Waddell PJ, and Hillis DM: Phylogenetic inference. Mol Syst 1996;2:407-414.

20. Posada D and Crandall KA: MODELTEST: Testing the model of DNA substitution. Bioinformatics 1998;14(9):817818.

21. Kumar S, Tamura K, and Nei M: MEGA: Molecular evolutionary genetics analysis software for microcomputers. CABIOS 1994;10:189-191. 
22. Kashima S, Alcantara LCJ, Takayanagui OM, et al.: Distribution of human $\mathrm{T}$ cell lymphotropic virus type 1 (HTLV-1) subtypes in Brazil: Genetic characterization of LTR and tax region. AIDS Res Hum Retroviruses 2006;22:953-959.

23. Mota ACA, Van-Dooren S, Fernandes FM, et al:: The close relationship between South Africa and Latin American HTLV-1 strains corroborated in a molecular epidemiological study of the HTLV-1 isolates from a blood donor cohort. AIDS Res Hum Retroviruses 2007;23:503-507.

24. Zehender G, Ebranati E, Bernini F, et al.: Phylogeny of human $\mathrm{T}$ cell lymphotropic virus type 1 in Peru: A high degree of evolutionary relatedness with South African isolates. AIDS Res Hum Retroviruses 2007;23: 1146-1149.

Address reprint requests to: Luiz Carlos Junior Alcantara LASP/CPqGM/FIOCRUZ

Rua Waldemar Falcão 121 Brotas, Salvador, Bahia Brazil 40295-001

E-mail: lalcan@cpqgm.fiocruz.br 